\title{
Characterization of the Pharmaceutical Risk-Sharing Arrangement Process in Catalonia
}

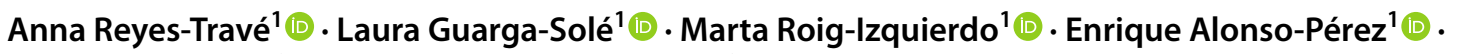 \\ Ana Clopés-Estela ${ }^{2} \cdot$ Joaquín Delgadillo-Duarte ${ }^{1,3}$ (1)
}

Accepted: 18 May 2021 / Published online: 10 June 2021

(c) The Author(s) 2021

\begin{abstract}
Pharmaceutical risk-sharing arrangements have emerged as a reasonable tool to promote sustainable access to innovative medicines with uncertain clinical evidence and/or economic impact from the payer perspective. These funding mechanisms pose an alternative option to the traditional fixed-price methods and are intended to align the price of medication with the value delivered in treating patients, balancing clinical need with affordability in the face of increasing therapeutic innovation and ever-tight budgets. The Catalan Health Service (CatSalut) has set up a systematic, traceable, and transparent methodology for the design and implementation of risk-sharing arrangements and 15 of such access schemes have been successfully implemented until December 2019. Our experience has acknowledged the need for a robust study design, appropriate financial, technical, and administrative resources, and strong stakeholder commitment and communication as critical to the success of risk-sharing arrangements. While the experience in Catalonia has been positive and has served to highlight the potential of such schemes in tackling public health policy concerns, this exchange can often be undermined by the lack of transparency surrounding risk-sharing arrangements and the fact that the literature related to their methodology, implementation, and impact is scarce. Further studies should be conducted and shared to address this obstacle.
\end{abstract}

\section{Key Points}

Pharmaceutical risk-sharing arrangements (RSAs) pose an alternative option to the traditional fixed-price methods and are intended to align the price of medication with the value delivered in treating patients, balancing clinical need with affordability in situations where uncertainties over a certain medicine are present.

This study provides an example on how to set up a systematic, traceable, and transparent methodology for the design and implementation of RSAs.

This study could inform other policy makers willing to set up a RSA methodology in their geographies, or provide new ideas for existing RSA processes.

Marta Roig-Izquierdo

maroig@ catsalut.cat

1 Servei Català de la Salut (CatSalut), Gran Via de les Corts Catalanes 591, 08007 Barcelona, Spain

2 Institut Català d'Oncologia (ICO), Hospitalet de Llobregat, Spain

3 Banc de Sang i Texits (BST), Barcelona, Spain

\section{Background}

Each year, a high number of innovative medicines are approved by the European Commission based on the European Medicines Agency's recommendation, triggering a wave of pricing and reimbursement decisions in each member state [1]. For Spain in particular, the pricing and reimbursement process and the inclusion of new drugs in the National Health System pharmaceutical repository are covered by the Spanish Ministry of Health [2]. However, because of the decentralized nature of the Spanish healthcare model, most budgetary, planning, and operative aspects of healthcare provision are managed by regional governments. Catalonia is the second largest region in Spain, with 7.7 million inhabitants $(16.3 \%$ of the Spanish population) and has a network of 65 public hospitals [3]. The Catalan Health Service (Servei Català de la Salut, henceforth, CatSalut) is the entity that ensures public access to the National Health System services in Catalonia. CatSalut operates through a multi-provider system known as the Integrated Public Healthcare System of Catalonia (SISCAT, its acronym in Catalan), according to the principles of equity, quality, and sustainability, 
by distributing and balancing resources according to the diverse needs of the population [4]. One of the responsibilities of CatSalut is to promote the rational use of drugs and ensure an efficient access to medicines across the Catalan territory.

Since the 1990s, many public healthcare systems worldwide have been assessing and implementing alternative funding mechanisms to the traditional fixed-price methods, such as pharmaceutical risk-sharing arrangements (RSAs), to accommodate access to novel medicines where there are uncertainties regarding their clinical effect on patients or their burden to health systems [5-7]. Risk-sharing arrangements are contracting schemes between healthcare payers and marketing authorization holders (MAHs) that link the access and cost of a therapeutic innovation to specific conditions of use or outcomes in clinical practice $[5,6]$. Therefore, the risks and uncertainties arising from public coverage are shared between the payer and the MAH [5-8]. The use of such arrangements has considerably increased over time in response to the increasing cost of innovation, particularly in the fields of oncology, neurology, and rheumatology [6], and the need to contain healthcare budgets while timely addressing unmet needs and ensuring patients access to novel therapies $[8,9]$.

According to the Professional Society for Health Economics and Outcomes Research [10], RSAs are largely divided into performance-based risk-sharing arrangements (PBRSAs) and cost-sharing arrangements (CSAs). Performance-based risk-sharing arrangements are broken down into (a) coverage with evidence development schemes, whose goal is to provide coverage while the evidence (i.e., additional population-level data) is developed to support continued or modified coverage and (b) performance-linked reimbursement schemes (PLRSs), whose goal is to manage utilization, aiming to control the cost effectiveness (CE) of a new technology in the real world [10]. Performance-linked reimbursement schemes include outcomes and money back guarantees (i.e., payment for responders only, refunds for non-responders), conditional treatment continuation (i.e., linked to intermediate endpoints), and/or payments related to the process of care (e.g., linked to compliance with clinical guidelines or on the basis of a biomarker) [10]. Cost-sharing arrangements include budget capping and/or utilization capping, variable or fixed discounts, and price-volume schemes [10].

CatSalut is guided by the strategic objectives and policies included in Catalonia's Health Plan, which in 2011 introduced flexible reimbursement systems for medicines linked to the achievement of agreed-upon results $[11,12]$. This led to a guided and gradual introduction of demo experiences (i.e., pilot or hospital-initiated RSAs) to acquire practical insight on the RSA implementation process. The first hospital-initiated RSA enrolled 41 patients and was signed in 2011 by the Catalan Institute of Oncology and a MAH for the introduction of a targeted therapy for the treatment of advanced non-small-cell lung cancer [13]. From 2011 to 2015 , more than 20 hospitals signed 12 independent hospital-initiated RSAs (ten in oncohematology and two in rheumatology). These were led by the hospitals themselves and self-managed in terms of clinical and financial assessment of the schemes, including administrative tasks such as the issuing of payments and refunds. This learning phase was critical to CatSalut and SISCAT to obtain valuable knowledge on contract elaboration, assess capability of existing databases to monitor drug use and cost, and shape stakeholder alignment and communication. In 2016, CatSalut took the lead from hospitals in the broader development, management, and implementation of RSAs for all SISCAT hospitals. A new centralized working dynamic was introduced, and a multidisciplinary working group for the development and management of RSAs was created. Risksharing arrangements were supported by a single contract between MAHs and CatSalut. Participation was automatic and mandatory for financial arrangements (i.e., CSAs), while participation in PBRSAs was initially bound to adhesion contracts signed between each reference hospital (i.e., hospital with the medical expertise required for the condition included in the PBRSA) and the MAH on a voluntary basis. However, in 2020, after a period where hospitals adapted to the collection of health outcomes, CatSalut made the participation of reference hospitals in PBRSAs automatic and mandatory, eliminating the need for adhesion contracts and making the process consistent between CSAs and PBRSAs. To systematically decide on the appropriateness of RSAs and settle the basis for their implementation through a robust step-by-step decision-making process, CatSalut developed a specific RSA guideline [14] in 2014, with the participation of academics and experts.

Despite the rising popularity of RSAs and the increasing availability of primary market research studies $[9,15$, $16]$, reviews $[6,7,17]$, and best-practice guidelines for their implementation [10], there are a very limited number of publications assessing the methodology, implementation, and long-term value and impact of RSAs worldwide [8, 13], which makes it difficult to learn from these experiences. The aim of this article is to describe the broad RSA process in Catalonia and to share our experience. 


\section{Drug Assessment, Selection, and Development of an Appropriate RSA}

\subsection{Drug Assessment and Identification of Uncertainties}

In 2008, CatSalut established its own drug appraisal program (PHF, its acronym in Catalan) [18], with the aim of guaranteeing equitable access to innovative medicines across the Catalan territory in accordance with the principles of rational drug use, and cognizant of the availability and optimization of resources. The PHF comprises two advisory councils, one for hospital outpatient drugs and one for primary care drugs (CAMH and CAMAPCE, respectively, their acronym in Catalan), and a decision-making commission (CFT-SISCAT, its acronym in Catalan). The three expert panels include members with different professional and clinical backgrounds (i.e., regional and hospital payers, hospital pharmacists, clinicians, health economists, bioethics experts, and patient representatives) to provide a holistic and multidisciplinary approach to drug assessment. Each panel counts on two representatives from different patient associations to ensure the patients' voice is heard at each step of the drug appraisal process. These individuals have been trained on administration procedures and their nomination is proposed by the Patient Advisory Council of Catalonia's Department of Health, which is the official body that represents patient organizations in front of the Catalan Administration [19]. Patient representatives provide their considerations on the clinical value of innovations at each drug appraisal but cannot execute their vote on appraisals concerning their own disease. Considerations of patients affected by the condition under study, including their medical and non-medical needs, expectations for new treatments, and the relevance that some of the results reported in clinical trials may have in their daily lives are collected through anonymous interviews conducted by evaluators for each drug appraisal. The different expert panel members are required to renew or ratify their positions every 3 years [18].

Based on the recommendations from the advisory councils, the CFT-SISCAT assesses the added value of innovative drugs and, particularly for hospital outpatient drugs, defines their conditions of use and access across the region in accordance to the medicine's clinical performance and cost considerations discussed during drug assessment [18]. Currently, there are three possible outcomes to this process: (1) use under specific clinical criteria defined by the CFTSISCAT, which can be aligned with or stricter than those of the authorized indication; (2) use under individual authorization, in which case treatment has to be approved by an expert committee case by case; or (3) exceptional use, if there is unfavorable or insufficient evidence to recommend its use. Drugs granted exceptional use- 19 of 280 drugs appraised by the PHF in their respective indications until December 2019 (6.8\%)—cannot be invoiced through regular channels (i.e., CatSalut does not reimburse these treatments to hospitals choosing to use these drugs), and therefore they have to be funded at the expense of the hospital's budget. The verdict of the CFT-SISCAT also stipulates the need for a managed access under a RSA where appropriate, which since 2020 has been linked to the automatic applicability of these schemes across the region.

The decision to establish a RSA for a particular drug in a given indication always arises from uncertainties identified by the PHF during the drug appraisal process. These uncertainties may be linked to clinical parameters (i.e., efficacy, effectiveness, safety) or economic parameters (i.e., budget impact [BI], CE). Clinical uncertainty is often related to the study design, clinical trial data, and its robustness, and alignment with real clinical practice. Similarly, financial uncertainty is often related to difficult estimates of the target population and $\mathrm{BI}$, possible indication extensions, and/ or lack of a fully established drug regimen and duration, among others (Table 1). CatSalut technicians assess the quality of economic evaluations conducted by the manufacturer as part of the routine exchange of information between CatSalut and the MAH prior to the medicine's appraisal by using CatSalut's Consolidated Health Economic Evaluation Reporting Standards (CHEERS) checklists [20]. Currently, the scope of RSAs in Catalonia is exclusively focused on hospital outpatient drugs because of their correlation with higher BIs and innovation.

\subsection{Working Group for the Development and Management of RSAs}

The group is composed of CatSalut professionals and representatives from healthcare providers, including clinicians, hospital pharmacists, regional and hospital payers, and health economists. Together, these members discuss the uncertainties to be tackled, as proposed by the CFTSISCAT, and define the most appropriate type of RSA in each case according to CatSalut's guideline for RSAs [14]. The guideline incorporates questionnaires to assess different clinical and financial dimensions, with items assessed according to relevance and level of uncertainty, including potential scenario mapping to establish the optimal RSA scheme to use in a given situation. For uncertainties concerning health outcomes, the proposed model is generally a PBRSA, to limit and share the risk of these uncertainties over time. Conversely, for uncertainties concerning financial outcomes, either associated with the treatment itself or the estimated target population, the proposed model is typically a CSA or conventional payment with a simple discount, to 
Table 1 Uncertainty type, scope, and considered variables for drug assessment

\begin{tabular}{lll}
\hline Uncertainty type & Uncertainty scope & Considered variables \\
\hline Clinical & Efficacy, effective- & Time frame \\
ness, and safety & Clinical trial phase \\
& Patient characteristics \\
& Primary endpoint \\
& Surrogate endpoints \\
& Active comparator \\
& Sensitivity analysis \\
& Statistical analysis \\
& Patient subgroup analyses \\
& Time frames for treatment \\
& follow-up \\
& Indication extension and \\
& concretion \\
& Treatment regimen \\
& Potentially replaceable \\
& treatments \\
& Net financial impact of \\
& treatment inclusion/ \\
& replacement \\
& Potential use extensions \\
& Other modifications in use \\
& of resources linked to new \\
& treatment \\
& Availability of CE or CU \\
& studies \\
&
\end{tabular}

Adapted from [14]

$B I$ budgetary impact, $C E$ cost-effectiveness, $C U$ cost-utility

limit and share the risk of an unexpected growth of BI, with potential restrictions to patient subgroups if there is strong evidence to support a greater drug value for a defined subgroup (Table 2). With regard to PBRSAs, clinicians with experience in the disease area are always invited ad hoc to share their expertise with the working group and support the proposals, by ensuring that the proposed clinical objectives, treatment response criteria, and treatment follow-up are consistent with daily clinical practice and available evidence. In contrast, for CSAs, ad hoc clinicians are only consulted to validate clinical aspects of the contract in the case of doubt (e.g., eligible criteria, number of cases, patient subgroups).

Once a customized proposal is agreed by the members of the working group, CatSalut presents a formal proposal to the MAH. At this point, terms and conditions are negotiated with the MAH for a fixed period of time that is set on a case-by-case basis (usually between 3 and 4 months), during which amendments can be made by both of the two parties until a final agreement is reached on both ends. Between 2016 and 2019, 25.0\% of the proposals were dismissed by MAHs, where a mutual agreement could not be reached. Eventually, this proposition, agreed upon by the working group and the MAH, is presented to the CFT-SISCAT for endorsement (Fig. 1).

\subsection{Agreement Formalization: Legally Binding Contracts}

Contracts containing the agreed terms and conditions are formalized by CatSalut and the respective MAH's legal departments, and then signed by representatives of all parties involved; usually CatSalut's Director and a top-level executive from the respective MAH. Contracts always include: (a) administrative criteria (i.e. contract validity period, contract renewal options), (b) clinical criteria (i.e., chosen medicine, indication, inclusion and exclusion criteria, treatment follow-up periods, variables and methods to measure treatment response, definition of treatment response), (c) economic conditions (i.e., conditions for rebates or discounts, due dates for refunds), (d) legal criteria (i.e., transparency, intellectual property, confidentiality), and (e) additional information regarding implementation steps (i.e., data sources, monitoring process including timeline for data analysis, typically every 12 months, matching calendar years, frequency of communication between CatSalut and the MAH).

Table 2 Decision rules for the definition of risk-sharing arrangements

\begin{tabular}{lll}
\hline Uncertainty type & Objectives & Proposed model \\
\hline $\begin{array}{l}\text { Uncertainty con- } \\
\text { cerning health } \\
\text { outcomes }\end{array}$ & $\begin{array}{c}\text { Limit and share the risk over short-term, medium-term, and } \\
\text { long-term health outcomes }\end{array}$ & PBRSA (e.g., PLRS or coverage with evidence development) \\
$\begin{array}{l}\text { Uncertainty } \\
\text { concerning } \\
\text { financial out- } \\
\text { comes }\end{array}$ & $\begin{array}{c}\text { Limit and share the risk of unexpected growth of estimated BI } \\
\text { due to variations in posology or treatment duration }\end{array}$ & $\begin{array}{c}\text { CSA (e.g., price volume, budget and/or utilization capping) } \\
\text { or conventional payment with simple discount based on } \\
\text { clinical outcomes }\end{array}$ \\
& $\begin{array}{c}\text { Limit and share the risk of unexpected growth of estimated BI } \\
\text { due to unforeseen use extensions and the patient population }\end{array}$ & $\begin{array}{c}\text { CSA (e.g., price volume, budget or/and utilization capping), } \\
\text { conventional payment with simple discount based on clini- } \\
\text { cal outcomes and/or access restriction concerning patient } \\
\text { subgroups }\end{array}$ \\
\hline
\end{tabular}

$B I$ budgetary impact, $C S A$ cost-sharing arrangement, $P L R S$ performance-linked reimbursement scheme, $P B R S A$ performance-based risk-sharing arrangement 


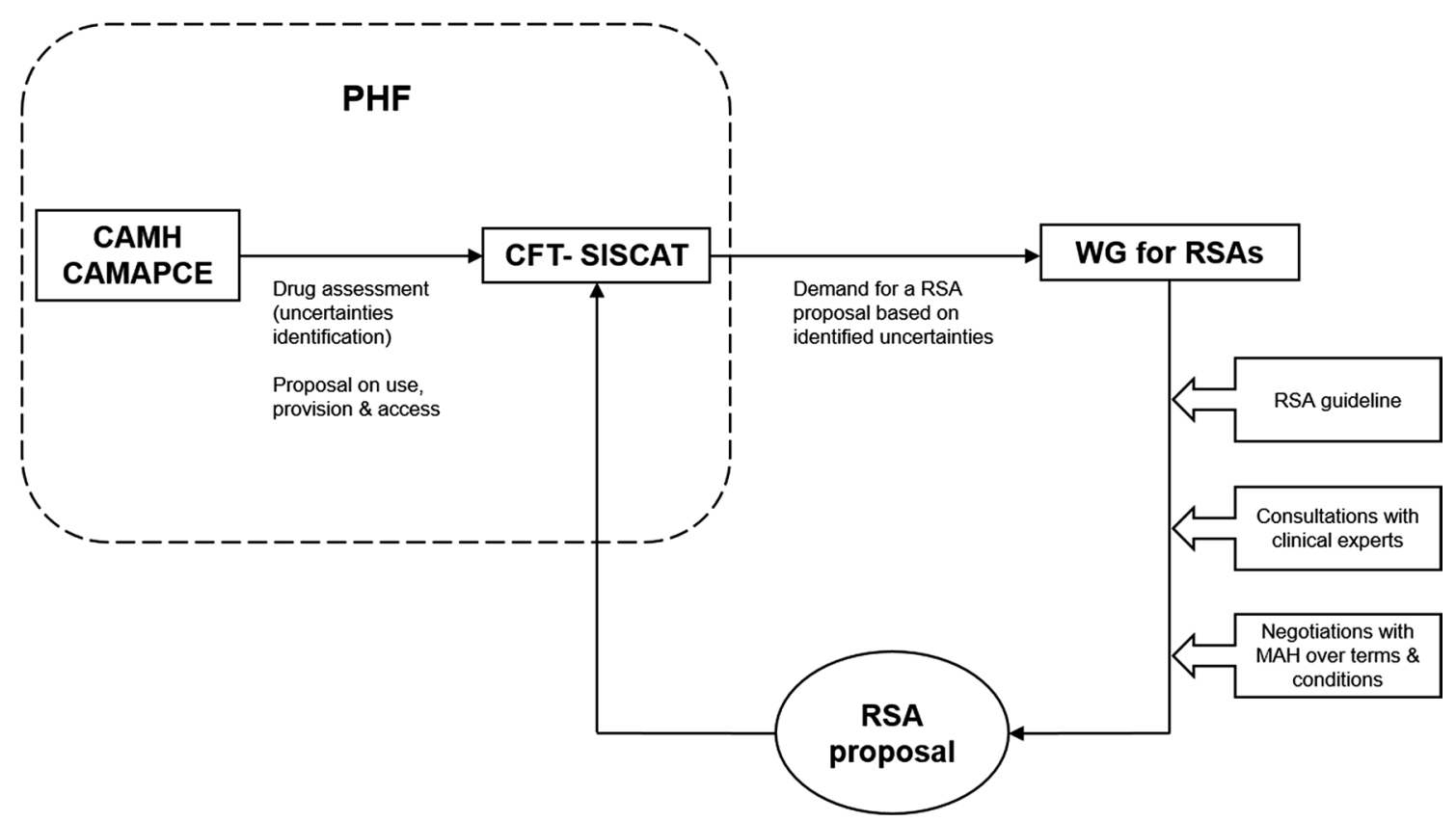

Fig. 1 Risk-sharing arrangement (RSA) development process. CAMAPCE Consell Assessor de Medicaments d'Atenció Primària i Comunitària i Atenció Especialitzada (advisory council for primary care drugs), CAMH Consell Assessor de Medicació Hospitalària (advisory council for hospital outpatient drugs), CFT-SISCAT Comis-

From 2016 to 2019, hospitals willing to participate in a PBRSA were required to sign additional contracts (i.e., adhesion contracts) with the MAH and inform CatSalut about their involvement. Incentives to adhere to PBRSAs included the potential savings generated from the arrangements (i.e., discounts and refunds for non-responsive patients in PBRSAs where the treatment was fully or partially paid by the manufacturer), but also the opportunity to promote the use of medicines best fit for patients as a result of stricter RSA terms. However, the establishment of a RSA did not necessarily penalize the pre-specified conditions of use and access established by the CFT-SISCAT for these medicines. Under certain circumstances (e.g., insufficient evidence on efficacy), the hospital's decision to not adhere to the RSA or the dismissal of the RSA proposal by the manufacturer prompted a shift in these conditions of use towards use under exceptional use, which could have a detrimental effect on hospitals' budgets. Over the 2016-19 period, 44 reference hospitals out of the 57 reference hospitals allowed to participate in PBRSAs signed adhesion contracts with MAHs (77.2\% adhesion rate). sió Farmacoterapèutica per al Sistema Sanitari Integral d'Utilització Pública de Catalunya (decision-making commission), $M A H$ marketing authorization holder, $P H F$ Programa d'Harmonització Farmacoterapèutica (drug appraisal program), $W G$ working group

\section{RSAs: Implementation and Follow-Up}

The implementation of PBRSAs and CSAs in Catalonia has been largely supported by the use of patient registries and online databases to monitor drug use and cost [21, 22].

\subsection{Monitoring Tools: Patient and Hospital Outpatient Drugs Treatment Registry and Invoicing for Health Services Application}

The Patient and Hospital Outpatient Drugs Treatment Registry (RPT-MHDA, its Catalan acronym) is a broad, specific, and centralized online registry for all SISCAT hospitals designed to systematically collect information on the use of innovative hospital outpatient drugs under conditions of routine clinical practice [21]. The RPT-MHDA provides information on (a) basic patient data (i.e., personal identification code, age, sex), (b) treatment (i.e., drug identification, therapeutic indication, initiation and termination date, prescribing hospital), (c) baseline patient characteristics, (d) follow-up clinical variables, and (e) discontinuation variables [21]. These variables provide the necessary information to assess compliance with the RSA criteria.

The Invoicing for Health Services Application (FSS, its acronym in Catalan) is an online database that monitors hospital outpatient drugs expenditure by registering and collecting billing data from each hospital and patient on a monthly 
basis [22]. The FSS includes variables on (a) patient identification (i.e., personal identification code, age, sex) and (b) hospital outpatient drug treatment (i.e., drug identification, dispensation or billing date, units, cost) [23]. Both databases are shared between hospitals and CatSalut, from which data are retrieved and presented in a spreadsheet-like format that facilitates data analysis.

\subsection{Data Analysis}

Data analysis is performed according to standards of observational studies [24, 25] and internal standard operating procedures. For PBRSAs, clinical data are retrieved via RPT-MHDA by identifying and selecting the study cohort according to the criteria defined in the agreement for the period under evaluation. Patients who do not meet the RSA criteria (i.e., eligible patient characteristics, measure of treatment response at established time points, without missing variables or registry errors) are excluded from the scheme. According to the treatment variables, patients are classified into one of four subgroups: (a) responsive (i.e., treatment variables meet contractual definition of clinical response), (b) non-responsive (i.e., treatment variables do not meet contractual definition of clinical response), (c) awaiting results (i.e., patients who have not yet reached the point for treatment follow-up), and (d) others (i.e., patients who discontinue the treatment because of reasons that are not covered by the agreement, for instance by patient's choice). Preliminary results are sent to the respective hospitals, which are required to validate or amend their patients' data via the online registry, and clarify any remaining doubts if needed. Descriptive analyses of health outcomes are performed with the validated data to assess: (a) patient demographic and baseline characteristics, (b) percentage of each patient category, and (c) treatment response rate. Descriptive analyses of economic consequences for PBRSAs and CSAs are conducted, considering the cost of total expenses and savings during the study period. Data on drug expenditure and invoiced drug quantities per each patient are retrieved and analyzed from the FSS. Limitations include the inability to analyze patient data that has not been registered by hospitals and/or has been introduced past the date of data collection.

\subsection{Qualitative Analysis: Follow-up Committees}

Follow-up committees for PBRSAs and CSAs are composed of CatSalut professionals, representatives of healthcare providers, and representatives of the MAH. In addition, follow-up committees for PBRSAs also include clinical experts in the therapeutic area. Every RSA has its own unique follow-up committee and the meetings are usually scheduled annually for standard year-to-year contracts.
The purpose of the follow-up meetings is to inform the MAH about the economic figures obtained for each RSA and the corresponding payments or refunds due to CatSalut according to the agreed terms. These are defined by the total drug cost for non-responsive cases for PBRSAs and paybacks generated through the establishment of economic agreements (e.g., fix discounts, expenditure ceilings) for CSAs. For PBRSAs, these meetings are also intended to share data on health outcomes and discuss the achieved results and overall experience of the parties involved (i.e., difficulties and areas for improvement spotted in the process). This step is particularly important for drugs whose PBRSA results seem to differ with the evidence based on pivotal clinical trials, PBRSAs in which an improvement of the clinical pathway could facilitate their implementation (e.g., by increasing the efficiency or availability of imaging resources), and/or PBRSAs where the agreed terms seem to not be in line with the daily clinical practice (e.g., there is a need to extend the period of time required to measure treatment response).

Descriptive analyses on health and financial outcomes are shared with manufacturers prior to the invoicing process. However, the results of these analyses are aggregated (i.e., by hospital and as a sum of all the participating hospitals) for anonymization purposes. Only CatSalut has full access to individualized patient data regarding each RSA. Hospital access is restricted to patients who have been treated in their facilities. Manufacturers do not have access to patients' data, in alignment with the European General Data Protection Regulation [26].

Based on the shared insights and conclusions reached by the follow-up committee, members propose next steps and actions aimed at deciding the future of each RSA. These can include decisions to: (a) add, withdraw, and/or amend any contractual clauses to better adjust treatment conditions or physician preferences to real-life practice (e.g., change of treatment response variable); (b) extend the agreement's validity period for an additional year (up to 4 years) if all parties are satisfied with previous experience and further evidence is still required; or (c) terminate the agreement if considered appropriate (e.g., the obtained data resolve the uncertainty that motivated the RSA). The renewal rate for RSAs established over the 2016-19 period was 73.3\%.

Moreover, upon the termination of a PBRSA and after the assessment of health outcomes, it is common practice to consider the need to negotiate a simple discount with the MAH that reflects the results, such as the unresponsiveness rate, acquired in real life during the course of the PBRSA. This offers the opportunity to further adjust the cost of the innovation covered by CatSalut according to the value the medicine has delivered in real-life clinical practice, thus bringing the price closer to the effectiveness observed in our setting for the specific indication under study. Hence, 
the economic conditions of the new agreement are linked to the value of the medicine [27]. Such negotiations are, nonetheless, based on trust and cooperativity between the parts and under no circumstance discounts are mandatorily and/or unilaterally applied on these medicines.

Results, discussion points, and agreed next steps for each RSA are formally compiled in a confidential post-meeting report that is shared internally with the working group and presented to the CFT-SISCAT.

\section{Lessons Learned from the Experience in Catalonia}

After nearly 10 years of experience, 12 hospital-initiated pilots, and 15 RSAs led by CatSalut (eight PBRSAs and seven CSAs) across SISCAT, on balance, the feedback has been positive from all participating stakeholders. The 15 RSAs implemented between 2016 and 2019 included 3017 patients across Catalonia. The introduction of these schemes has encouraged a working dynamic that links the existing drug appraisal process with reimbursement models, providing an opportunity to assess the real-word clinical and financial performance of new drugs in a controlled setting [14]. This has ultimately led to the sustainable incorporation of innovation for patients under conditions that are considered optimal by payers, clinicians, and manufacturers [13]. The potential benefits of agreements that involve a risk-sharing element have not only come from gains in savings (2.4 M€ worth of refunds made by MAHs for all RSAs implemented between 2016 and 2019, representing a 3.8\% of the total spending on medicines subject to RSAs throughout this period), but most importantly, from a more efficient use of medicines and the ability to identify, reduce, and share initial uncertainties on clinical outcomes and/or financial impact in the real world among participants.

Risk-sharing arrangement-generated real-world data have proven to be a powerful feedback tool used by decision makers to contrast and assess the alignment between real-world evidence and clinical trials $[8,10]$. Moreover, in the long term, data generated from the implementation of such schemes have contributed, in some cases, to transform quantified uncertainties into actual discounts for payers and providers, helping to modulate targets according to realworld insights. In Catalonia, PBRSA-generated real-world data have been used to re-assess and modify CFT-SISCAT's recommendations and conditions of use for some of these medicines (12.5\% of PBRSAs performed between 2016 and 2019). As for manufacturers, RSAs constitute an opportunity to gather experience and real-world data on their products, as well as a chance to learn about new methods and mechanisms to promote access for additional innovations in the future.
The successful establishment of RSAs in Catalonia has entailed a number of associated challenges and costs in terms of staff time, information technology, and diagnostic resources. Associated costs for these are unclear as all of these assets are not exclusive to RSAs. However, a proof of concept for the feasibility of establishing valid and efficient evidence collection processes through good professional practices to assess acceptable levels of uncertainty has successfully been established.

Our experience has shown that being in possession of reliable, functioning, and well-suited databases for the collection of clinical and financial data of medicines included in RSAs is the first and most important step, also a limiting factor, to securing a successful RSA implementation. The more standardized and systematic the process of data collection is, the timelier, more simplified, and trustworthy will be the analysis.

Risk-sharing arrangements should always strive for clinical robustness and plausibility, appropriate real-world context, and easy monitoring of outcomes [7, 10, 28]. The design and implementation of RSAs require a well-thoughtout approach from the start, clear governance structures, and the commitment of all stakeholders. It is critical that the study design and the evidence being generated from RSAs are sufficient to address the uncertainties that are making payers reluctant to reimburse or recommend the drug in both quantitative and qualitative terms (i.e., backed by data analysis and stakeholders' expertise) [10].

To improve and optimize the overall RSA process, the working group has been refining its procedures to facilitate the implementation, analysis, and understanding of RSAs at regional and hospital levels. Steps have been taken towards avoiding interference in data analyses (e.g., by redefining and creating new treatment variables) and minimizing the administrative burden, by improving RPT-MHDA usability, performance, and overall quality [21], providing training to healthcare professionals, and creating protocols to ensure traceable and systematic data analyses, with the incorporation of preliminary information cross-checks with participating hospitals.

Last, our experience has demonstrated that a final evaluation of the long-term impact of each RSA on the overall healthcare system's efficiency, involving the sharing of data and knowledge among healthcare professionals, payers, and MAHs is highly beneficial and key for the learning process. This multidimensional exercise allows for the assessment of many factors such as the impact on effectiveness, whether appropriate evidence was generated to reduce uncertainty and support decision making, whether budget and time were appropriate, and whether the governance arrangements worked well, while posing a valuable opportunity for suggesting improvements and bringing an overall sense of purpose among participants $[10,14]$. In addition, our experience 
has evinced that mutual trust between stakeholders is the mainstay for building cooperative relationships and navigating the unexpected events that can emerge from these access schemes (e.g., change in pricing and reimbursement conditions, modifications on CFT-SISCAT criteria for use based on an updated appraisal).

\section{Areas for Improvement and Future Challenges}

As prices of innovative drugs continue to rise and uncertainties related to immature data at approval time are frequently present, the more relevant and challenging it becomes to improve and adapt existing RSA methodologies to ensure access while mitigating uncertainty, balancing clinical need with affordability $[10,17]$. It is important to persevere at streamlining the bureaucratic process, maximizing patient access to healthcare resources, and promoting the involvement and debate of healthcare professionals through educational activities and/or international conventions to foster connectivity. It is essential to implement good research practices that are results oriented and able to adapt to new situations and treatments that require different and changing clinical and economic set-ups [10]. An example of this could be the establishment of joint RSAs for competing products in the same indication or the establishment of RSAs for multiindication medicines. In our experience on the latter, CatSalut has established CSAs for multi-indication products in cases where the drug was linked to economic uncertainty, by establishing a fixed discount for the product across its range of connected indications. However, for multi-indication products in which specific indications were linked to clinical uncertainty, CatSalut has opted for the establishment of indication-specific PBRSAs, thus treating each indication separately.

Because of the considerable academic input during the creation of our RSA guideline, some recommendations, especially those targeting economic evaluations, were framed in a more academic set-up, reflecting an ideal scenario where all clinical evidence and economic parameters (i.e., incremental $\mathrm{CE}$ and/or cost-utility ratios, willingness to pay) were known and available to the payers. However, the reality has been that not all of these data have been available to the payers at the time of decision making. Therefore, there is a need to seek further alignment between the theoretical methodology captured in our guidelines and the day-to-day reality of operating such entry arrangements. In this sense, steps have been taken towards a wider applicability of complete economic evaluations as part of the routine appraisal process by the PHF in Catalonia.

It would also be interesting to determine whether public healthcare systems could benefit from extending the scope of
RSAs to primary care drugs. However, from our experience, existing co-payment hurdles for these drugs, their generally large target populations, and their significantly lower levels of BI-at least in terms of cost per patient-make it difficult to implement innovative contracting strategies such as PBRSA for their access. Likewise, there is an ongoing international debate about whether the incorporation of patientreported outcomes in addition to clinical response criteria in PBRSA, which are currently not captured in routine clinical practice, could also be appropriate [28].

\section{Conclusions}

More than ever, healthcare systems require flexible models that allow alignment between the price of medicines and the value they deliver in treating patients. The increasing availability of costly innovative therapies associated with clinical and economic uncertainties has made RSAs a reasonable response to increasing pressure for greater evidence of real-world effectiveness and CE. Thus, CatSalut has set up a systematic, traceable, and transparent methodology for the design and implementation of RSAs and 15 of such access schemes have been successfully implemented until December 2019. Our experience has acknowledged the need for a robust study design, appropriate financial, technical and administrative resources, and strong stakeholder commitment and communication as critical to the success of RSAs. There are many reasons to be optimistic about the potential of these schemes as a key tool to promote sustainable access of medicines in the current budget-constrained climate; however, this is often undermined by the lack of transparency surrounding these schemes and the scant information that is available regarding national or regional experiences. Further studies assessing the methodology, implementation, and impact of RSAs should be conducted and shared to address this obstacle.

Acknowledgements The authors thank all SISCAT professionals for their effort and contribution to the successful implementation of RSAs in Catalonia, especially the Institut Català d'Oncologia (ICO) for the additional initial support. The development of these agreements would have been impossible without the drive and leadership of Antoni Gilabert and Cristina Espinosa, as well as the continuous support and valuable input from the current and former members of the working group for the development and management of RSAs. The authors would also like to warmly acknowledge all the colleagues from Servei Català de la Salut's (CatSalut's) Gerència del Medicament, Divisió Econòmica del Medicament, Regions Sanitàries, Àrea de Sistemes d'Informació, and Assessoria Jurídica, especially Caridad Pontes, Manel Fontanet, Montserrat Gasol, Josep Torrent, and Ivan Planas, for their dedication and contribution to the development, implementation, and management of these schemes. 


\section{Declarations}

Funding No financial support was received for the preparation of this article.

Conflict of interest Reyes-Travé A., Guarga-Solé L., Roig-Izquierdo M., Alonso-Pérez E., Clopés-Estela A., and Delgadillo-Duarte J. have no conflicts of interest that are directly relevant to the content of this article.

Authors' contributions RTA, GSL, RIM, and APE contributed to the planning and design of the article. RTA conducted the literature review, developed the figures and tables, and was responsible for writing the first draft and the final version of the manuscript based on the comments received from GSL, RIM, APE, CEA, and DDJ. GSL co-conducted the literature review and collaborated in the development of the tables, structure, and content of the text. CEA established the pilot RSAs and DDJ coordinated the implementation of RSAs in Catalonia. RIM and GSL participated in the design and implementation of RSAs, and RTA and APE supported their implementation. All authors critically reviewed and approved the final submitted version of the manuscript.

Open Access This article is licensed under a Creative Commons Attribution-NonCommercial 4.0 International License, which permits any non-commercial use, sharing, adaptation, distribution and reproduction in any medium or format, as long as you give appropriate credit to the original author(s) and the source, provide a link to the Creative Commons licence, and indicate if changes were made. The images or other third party material in this article are included in the article's Creative Commons licence, unless indicated otherwise in a credit line to the material. If material is not included in the article's Creative Commons licence and your intended use is not permitted by statutory regulation or exceeds the permitted use, you will need to obtain permission directly from the copyright holder. To view a copy of this licence, visit http://creativecommons.org/licenses/by-nc/4.0/.

\section{References}

1. European Medicines Agency. Authorisation of medicines. https:// www.ema.europa.eu/en/about-us/what-we-do/authorisation-medic ines. Accessed 25 Sept 2020.

2. Ministerio de Sanidad, Consumo y Bienestar Social. Funciones Dirección General de Cartera Básica de Servicios del Sistema Nacional de Salud y Farmacia. https://www.mscbs.gob.es/organ izacion/ministerio/organizacion/sgralsanidad/dgcbssnsyfF.htm. Accessed 25 Sept 2020.

3. Generalitat de Catalunya. The CatSalut. https://catsalut.gencat. cat/ca/coneix-catsalut/index.html\#googtrans(calen). Accessed 25 Sept 2020.

4. Generalitat de Catalunya. Decret 118/2014, de 5 d'agost, sobre la contractació i prestació dels serveis sanitaris amb càrrec al Servei Català de la Salut. https://portaldogc.gencat.cat/utilsEADOP/ PDF/6681/1368383.pdf. Accessed 25 Sept 2020.

5. Carlson JJ, Sullivan SD, Garrison LP, Neumann PJ, Veenstra DL. Linking payment to health outcomes: a taxonomy and examination of performance-based reimbursement schemes between healthcare payers and manufacturers. Health Policy. 2010;96:179-90.

6. Carlson JJ, Chen S, Garrison LP. Performance-based risk-sharing arrangements: an updated international review. Pharmacoeconomics. 2017;35:1063-72.
7. Ferrario A, Araja D, Bochenek T, Tarik C, Danko D, Dimitrova $\mathrm{M}$, et al. The implementation of managed entry agreements in Central and Eastern Europe: findings and implications. Pharmacoeconomics. 2017;35:1271-85.

8. Gonçalves FR, Santos S, Silva C, Sousa G. Risk-sharing agreements, present and future. Ecancermedicalscience. 2018;12:823.

9. Dunlop WCN, Staufer A, Levy P, Edwards GJ. Innovative pharmaceutical pricing agreements in five European markets: a survey of stakeholder attitudes and experience. Health Policy. 2018;122(5):528-32.

10. Garrison LP, Towse A, Briggs A, De Pouvourville G, Grueger J, Mohr PE, et al. Performance-based risk-sharing arrangements: good practices for design, implementation, and evaluation: report of the ISPOR Good Practices for Performance-Based Risk-Sharing Arrangements Task Force. Value Health. 2013;16:703-19.

11. Generalitat de Catalunya. Departament de Salut. Health plan for Catalonia 2011-2015. https://salutweb.gencat.cat/web/.content/_ departament/pla-de-salut/Plans-de-salut-anteriors/Pla-de-salut-deCatalunya-2011-2015/pla-de-salut-2011-2015/documents/health_ plan_english.pdf. Accessed 21 Feb 2021.

12. Generalitat de Catalunya. Departament de Salut. Health plan for Catalonia 2016-2020. https://salutweb.gencat.cat/web/.content/_ departament/pla-de-salut/Pla-de-salut-2016-2020/documents/ health-plan-catalonia_2016_2020.pdf. Accessed 21 Feb 2021.

13. Clopes A, Gasol M, Cajal R, Segú L, Crespo R, Mora R, et al. Financial consequences of a payment-by-results scheme in Catalonia: gefitinib in advanced EGFR-mutation positive non-small-cell lung cancer. J Med Econ. 2017;20(1):1-7.

14. Clopes A, Espinosa C, Gasol M, Gilabert A, Puig-Junoy J, Rubio A, et al. Guia per a la definició de criteris d'aplicació d'esquemes de pagament basats en resultats (EPR) en l'àmbit farmacoterapèutic (acords de risc compartit). Versió 1.0. CatSalut. 2014. https:// catsalut.gencat.cat/web/.content/minisite/catsalut/proveidors_ professionals/medicaments_farmacia/acords-risc-compartit/guiadefinicio-criteris-aplicacio-esquemes-pagament-resultats-epr.pdf. Accessed 25 Sept 2020.

15. Goodman C, Villarivera C, Gregor K, Van Bavel J. Regulatory, policy, and operational considerations for outcomes-based risksharing agreements in the U.S. market: opportunities for reform. J Manag Care Spec Pharm. 2019;25(11):1174-81.

16. Lorente R, Antonanzas F, Rodriguez-Ibeas R. Implementation of risk-sharing contracts as perceived by Spanish hospital pharmacists. Health Econ Rev. 2019;9:25.

17. Antonanzas F, Juárez-Castelló C, Lorente R, Rodríguez-Ibeas R. The use of risk-sharing contracts in healthcare: theoretical and empirical assessments. Pharmacoeconomics. 2019;37:1469-83.

18. CatSalut. Instrucció $05 / 2017$, Programa d'harmonització farmacoterapèutica del CatSalut. https://scientiasalut.gencat.cat/bitst ream/handle/11351/2965/catsalut_instruccio_05_2017.pdf?seque nce $=1 \&$ isAllowed $=y$. Accessed 25 Sept 2020 .

19. Generalitat de Catalunya. Consell Consultiu de Pacients. https:// salutweb.gencat.cat/ca/ambits_actuacio/per_perfils/Consell_pacie nts/el_consell_pacients/. Accessed 30 Apr 2021.

20. Puig-Junoy J, Oliva-Moreno J, Trapero-Bertran M, AbellánPerpiñán JM, Brosa-Riestra M. Guia i recomanacions per a la realització i presentació d'avaluacions econòmiques i anàlisis d'impacte pressupostari de medicaments en l'àmbit del CatSalut. 2014. https://catsalut.gencat.cat/web/.content/minisite/catsalut/ proveidors_professionals/medicaments_farmacia/farmaecono mica/caeip/gaeip_publica_catala_octubre2014_catsalut.pdf. Accessed 21 Feb 2021.

21. Roig-Izquierdo M, Prat-Casanovas MA, Gorgas-Torner MQ, Pontes-García C. Registry of patients and treatments of hospital medicines in Catalonia (Spain): 10 years of clinical data. Med Clin (Barc). 2020;154(5):185-91. 
22. CatSalut. Instrucció $01 / 2011$, Criteris i condicions per a l'adequació de la indicació i condicions d'utilització de medicaments d'acord amb els informes dels comitès d'experts. Registre i seguiment clínic. Verificació i acreditació de les condicions de provisió i finançament pel CatSalut. 2011. https://scientiasalut. gencat.cat/bitstream/handle/11351/1329/catsalut_instruccio_01_ 2011.pdf?sequence=1\&isAllowed=y. Accessed 25 Sept 2020.

23. Generalitat de Catalunya. Aplicacions disponibles. https://catsa lut.gencat.cat/ca/proveidors-professionals/portal-aplicacions/aplic acions-disponibles/. Accessed 25 Sept 2020.

24. Von Elm E, Altman DG, Egger M, Pocock SJ, Gøtzsche PC, Vandenbroucke JP. The Strengthening the Reporting of Observational Studies in Epidemiology (STROBE) statement: guidelines for reporting observational studies. J Clin Epidemiol. 2008;61:344-9.

25. Benchimol EI, Smeeth L, Guttmann A, Harron K, Moher D, Petersen I, et al. The REporting of studies Conducted using
Observational Routinely-collected health data (RECORD) statement. PLoS Med. 2015;12(10):e1001885.

26. European Commission. Regulation (EU) 2016/679 of the European Parliament and of the Council of 27 April 2016 on the protection of natural persons with regard to the processing of personal data and on the free movement of such data, and repealing Directive 95/46/EC (General Data Protection Regulation). https://eurlex.europa.eu/legal-content/EN/TXT/PDF/?uri=CELEX:02016 R0679-20160504\&from=EN. Accessed 21 Feb 2021.

27. Porter ME. What is value in health care? N Engl J Med. 2010;363(26):2477-81.

28. Cole A, Cubi-Molla P, Pollard J, Sim D, Sullivan R, Sussex J, et al. Making outcome-based payment a reality in the NHS. https://www.cancerresearchuk.org/sites/default/files/obp_final_ report_pdf.pdf. Accessed 25 Sept 2020. 